$10^{\text {th }}$ International Conference on Modern Research in

MANAGEMENT, ECONOMICS and ACCOUNTING

20-22 March, 2020 Berlin, GERMANY

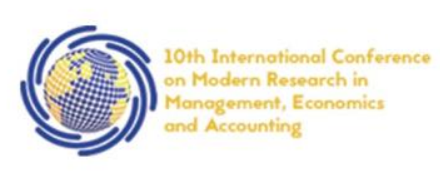

\title{
The Modified Mondragon Model And the Necessary Demise of the Current Corporate Form
}

\author{
Stephen Douglas Beets \\ Wake Forest University
}

\begin{abstract}
As currently designed, the business corporation is primarily designed for one simple purpose: the enrichment of stockholders. Considering the immense size and wealth of many modern corporations, however, this prioritized focus has deleterious ethical consequences, including a burgeoning wealth gap between those who own or manage the corporation and employees. Several individuals and organizations, such as the Business Roundtable, are calling for a redesign of the business corporation to benefit many who are affected by business organizations, such as employees and communities. As corporations are a government construct, national governments can serve a large proportion of their citizenry with an enhanced and innovative corporation design. One such design which may be an improvement on the status quo was developed in the 1950s in the village of Mondragon, Spain. This model is employee-owned with extensive profit-sharing, employee training, limits on executive compensation, and financial support for programs of the surrounding community. To illustrate the differences between the status quo corporation and the Mondragon model, financial and accounting information is presented of a sample of large, moderate, and small corporations of the Fortune 500 under both systems, as well as comparative information regarding salaries and stock.
\end{abstract}

Keywords: corporation design, Mondragon, employee-owned, wealth gap 